\title{
Factors that influence exhaled nitric oxide in Italian schoolchildren
}

Fabio Cibella, MD*; Giuseppina Cuttitta, MD†; Stefania La Grutta, MD\$; Giovanni Passalacqua, MD and Giovanni Viegi, MD*\|

Background: Conflicting results exist about the meaning of exhaled nitric oxide (eNO) in epidemiologic studies, mainly because of the numerous factors that may affect the measurement.

Objectives: To evaluate the role of the factors that influence eNO levels in a sample of schoolchildren with or without respiratory diseases. We studied 335 schoolchildren, ages 10 to 16 years, from 8 schools in Palermo, Italy. After a respiratory questionnaire was completed, spirometry, skin tests, and eNO measurements were performed.

Results: Among 335 children, $13.7 \%$ reported symptoms of bronchial asthma, 46.9\% reported symptoms of rhinitis, and $39.4 \%$ were asymptomatic. The ratio of forced expiratory volume in 1 second to forced vital capacity was $87.6 \%$ (SD, $6.4 \%)$ in the bronchial asthma group, $90.6 \%$ (SD, 5.0\%) in the rhinitis group, and $90.4 \%$ (SD, 5.1\%) in the asymptomatic group $(P<$ .002 ). Atopic children constituted $52.2 \%$ of the bronchial asthma group, $40.1 \%$ of the rhinitis group, and $28.8 \%$ of the asymptomatic group. Among atopic children, $102(82 \%)$ had a positive skin test result for Dermatophagoides. Median eNO was $12.6 \mathrm{ppb}$ in nonatopic children and $21.2 \mathrm{ppb}$ in atopic children $(P<.001$, by Mann-Whitney $U$ test $)$. Among asymptomatic children, atopic children had significantly higher eNO levels than did nonatopic children $(P<.001)$. In nonatopic children, no difference was found in $\log$ transformation eNO among healthy, rhinitic, or asthmatic children. Log transformation eNO increased with the number of positive skin test results $(P<.001)$. Atopy, asthma, male sex, and indoor allergens were predictors of increased eNO in a logistic model.

Conclusions: Atopy (in particular, sensitization to indoor and perennial allergens) is strongly associated with higher eNO levels. Such association is enhanced by asthma.

Ann Allergy Asthma Immunol. 2008;101:407-412.

\section{INTRODUCTION}

Exhaled nitric oxide (eNO) has been proposed as a noninvasive marker of airway inflammation in asthma and respiratory allergy, and its use is currently increasing, in view of its relatively simple procedure. The latter represents an additional advantage, especially in the pediatric population. Furthermore, the measurement of eNO has been suggested as a valuable tool in adjusting asthma therapy according to inflammation. Increased levels of eNO have been found in asthmatic children ${ }^{1}$ and in asymptomatic atopic children..$^{2-4}$ Consequently, it has been suggested that the relation between asthma and increased eNO levels may be mediated by atopy itself. ${ }^{5}$ This suggestion emphasizes the key role of atopic inflammation in determining an increase in eNO production for allergic diseases such as asthma and rhinitis. ${ }^{6,7}$

Affiliations: * Consiglio Nazionale delle Ricerche, Istituto di Biomedicina e Immunologia Molecolare, Palermo, Italy; $\uparrow$ Consiglio Nazionale delle Ricerche, Istituto di Biomedicina e Immunologia Molecolare, Palermo, Italy; $\ddagger$ Consiglio Nazionale delle Ricerche, Istituto di Biomedicina e Immunologia Molecolare, and Health and Environment Unit, Environment Regional Agency-ARPA-Sicilia, Palermo, Italy; § Allergy and Respiratory Diseases, Dipartimento di Medicina Interna, University of Genoa, Genoa, Italy; || Consiglio Nazionale delle Ricerche, Unità di Epidemiologia Ambientale Polmonare, Istituto di Fisiologia Clinica, Pisa, Italy.

Disclosures: Authors have nothing to disclose.

Received for publication February 28, 2008; Received in revised form April 11, 2008; Accepted for publication April 21, 2008.
Nevertheless, some conflicting results exist about the meaning of eNO measures in epidemiologic studies. In fact, some authors did not find any difference in eNO levels between atopic and nonatopic healthy individuals. ${ }^{1,8} \mathrm{Con}-$ versely, other studies demonstrated a linear or dose-response relation between the degree of skin test positivity and eNO levels. ${ }^{2,4,7}$ The relative weight of some factors (atopy, clinical disease, number of positive skin test results) remains to be determined. The aim of the present study was to identify the determinants of high eNO levels in a sample of schoolchildren with and without respiratory disease.

\section{METHODS}

\section{Patient Population}

This was a cross-sectional study conducted in a sample of schoolchildren, ages 10 to 16 years, from 8 junior high schools in Palermo, Southern Italy, in 2004. The whole student population of the 8 schools was 4,711 children. Among them, we randomly selected 1,177 children for the study (1 for every 4). One hundred twenty-seven children did not obtain parental consent or were not present at school on the day of the study. Thus, 1,050 children completed the respiratory health questionnaire ${ }^{9}$ and underwent lung function testing and skin prick testing at school. One third of 1,050 children ( 1 of every 3 children; total, 350 ) were selected for eNO testing in our laboratory. Fifteen children were excluded because of recent upper or lower respiratory tract infections 
Table 1. Descriptive Data of the Total Sample and Study Population ${ }^{\mathrm{a}}$

\begin{tabular}{|c|c|c|}
\hline Variable & $\begin{array}{l}\text { Total sample } \\
(\mathrm{N}=1,050)\end{array}$ & $\begin{array}{l}\text { Study population } \\
\qquad(\mathrm{n}=335)\end{array}$ \\
\hline Female/male, No. & $573 / 477$ & $191 / 144$ \\
\hline Age, mean (range), y & $12.2(10-17)$ & $12.1(10-16)$ \\
\hline Asthmatic, No. (\%) & $129(12.3)$ & $46(13.7)$ \\
\hline Rhinitic, No. (\%) & $491(46.8)$ & $157(46.9)$ \\
\hline Control, No. (\%) & $430(40.9)$ & $132(39.4)$ \\
\hline Atopy, No. (\%) & $329(31.3)$ & $125(37.3)$ \\
\hline FVC, mean (SD), L & $3.06(0.64)$ & $2.97(0.58)$ \\
\hline $\begin{array}{l}\text { FVC, mean (SD), } \\
\text { \% predicted }\end{array}$ & $98.7(11.8)$ & $98.0(11.5)$ \\
\hline $\mathrm{FEV}_{1}$, mean (SD), L & $2.74(0.55)$ & $2.66(0.49)$ \\
\hline $\begin{array}{l}\mathrm{FEV}_{1} \text {, mean }(\mathrm{SD}) \\
\% \text { predicted }\end{array}$ & $99.0(11.6)$ & $98.7(10.8)$ \\
\hline $\mathrm{FEV}_{1} / \mathrm{FVC}$, mean (SD), \% & $89.7(5.7)$ & $90.1(5.34)$ \\
\hline $\begin{array}{l}\mathrm{FEV}_{1} / \mathrm{FVC} \text {, mean (SD), } \\
\% \text { predicted }\end{array}$ & $100.5(6.2)$ & $100.9(5.9)$ \\
\hline
\end{tabular}

Abbreviations: FVC, forced vital capacity; $\mathrm{FEV}_{1}$, forced expiratory volume in 1 second.

${ }^{\text {a }}$ All differences are not statistically significant $\left(\chi^{2}\right.$ test for categorical variables and analysis of variance for continuous variables).

or insufficient cooperation in performing eNO measures. Thus, we obtained eNO measurements in 335 children. Except for asthma, no other chronic pulmonary disease was reported, and no child was taking oral or inhaled steroids. The study was approved by the institutional ethics committee. All parents of the children signed a written informed consent form. According to Italian law, respect for individual privacy concerning clinical data was granted.

\section{Study Parameters}

A history of physician-diagnosed asthma was defined as a positive answer to the question, "Have you ever had asthma diagnosed by a physician?" Rhinitis was defined as a positive answer to the question, "Have you ever had sneezing, or runny, or blocked nose apart from common cold or flu?" Based on these criteria, children were subdivided into 3 subgroups: asthmatic children, rhinitic children, and control children, that is, children without asthma or rhinitis.
Skin tests were performed according to international recommendations with a standard panel, including Dermatophagoides mix, grass mix, Parietaria judaica, Compositae mix, olive, dog and cat dander, Alternaria, and Blattella germanica, plus a positive (histamine 1\%) and a negative (saline) control (Stallergènes Italia S.r.l., Milan, Italy). The positivity was measured after 15 minutes, and reactions were considered positive if the wheal was $3 \mathrm{~mm}$ or greater in its larger diameter, in the presence of a negative reaction to the saline control..$^{10}$ Atopy was defined as the presence of at least 1 positive skin prick test result. Children were grouped into 3 different groups according to the number of the positive skin prick test results: nonatopic, 1 positive skin prick test result, or 2 or more positive skin prick test results.

Height and weight were measured in all the children, and body mass index was calculated as weight in kilograms divided by height in meters squared. Pulmonary function tests were performed with the use of a portable spirometer (MicroLoop, Micro Medical; Chatham Maritime, Kent, England). Forced expiratory volume in 1 second $\left(\mathrm{FEV}_{1}\right)$ and forced vital capacity (FVC) were measured according to American Thoracic Society guidelines, and the best (largest sum of FVC and $\mathrm{FEV}_{1}$ ) of 3 technically acceptable and reproducible maneuvers was retained. ${ }^{11}$

\section{Nitric Oxide Measurements}

On a different day, fractional eNO concentrations were measured in our medical laboratory by a chemiluminescence analyzer connected to a computerized system (NIOX; Aerocrine AB, Stockholm, Sweden). The instrument had a sensitivity of $1.5 \mathrm{ppb}$, a detection range of 0 to $200 \mathrm{ppb}$, and a response time less than 0.8 second. The instrument was calibrated with a certified NO gas mixture. The online single exhalation technique provided automatic control of exhalation to a constant flow rate of $50 \mathrm{~mL} / \mathrm{s}$, according to American Thoracic Society recommendations. ${ }^{12}$ During exhalation, positive pressure provided closure of the velum, preventing contamination of the sample with nasal NO. The mean eNO value of 3 valid measurements was recorded for each participant.

Table 2. Atopy, Respiratory Function, and eNO Data for Each Clinical Subgroup

\begin{tabular}{lccc}
\hline \multicolumn{1}{c}{ Variable } & $\begin{array}{c}\text { Control patients } \\
(\mathbf{n}=\mathbf{1 3 2})\end{array}$ & $\begin{array}{c}\text { Rhinitic patients } \\
(\mathbf{n}=\mathbf{1 5 7})\end{array}$ & $\begin{array}{c}\text { Asthma patients } \\
(\mathbf{n}=\mathbf{4 6})\end{array}$ \\
\hline Atopic children, No. (\%) & $38(28.8)^{\mathrm{a}}$ & $63(40.1)^{\mathrm{a}}$ & $24(52.2)^{\mathrm{a}}$ \\
$\mathrm{FEV}_{1} / \mathrm{FVC}$, mean (SD), \% & $90.4(5.10)$ & $90.6(5.03)$ & $87.6(6.41)^{\mathrm{b}}$ \\
$\mathrm{FEV}_{1}$ /FVC, mean (SD), \% predicted & $101.5(5.5)$ & $101.3(5.5)$ & $97.9(7.0)^{\mathrm{b}}$ \\
eNO in atopic children, median (range), ppb & $17.4(5.5-95.2)$ & $19.1(5.8-92.5)$ & $48.8(8.2-88.0)^{\mathrm{c}}$ \\
eNO in nonatopic children, median (range), ppb & $13.1(3.0-71.0)$ & $12.6(2.8-71.8)$ & $11.0(3.8-28.9)$ \\
\hline
\end{tabular}

Abbreviations: eNO, exhaled nitric oxide; FVC, forced vital capacity; FEV ${ }_{1}$, forced expiratory volume in 1 second.

a $P=.01$ ( $\chi^{2}$ test).

${ }^{\mathrm{b}} P=.002$ compared with controls and rhinitic children (analysis of variance).

${ }^{\mathrm{c}} P<.001$ compared with controls and rhinitic children (Mann-Whitney $U$ test). Unless otherwise indicated, differences are not significant. 


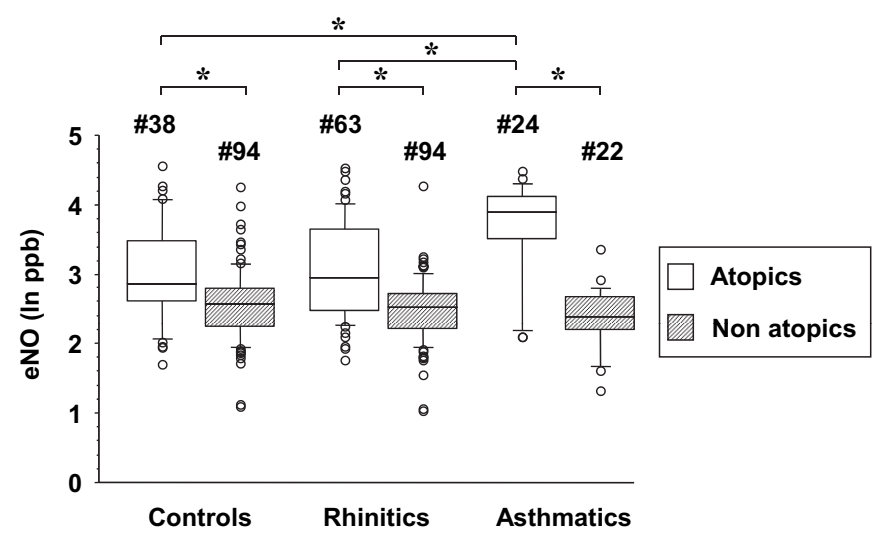

Figure 1. Values of exhaled nitric oxide (eNO) (as natural log) in atopic and nonatopic children of each subgroup: asymptomatic (control) children, rhinitic children, and asthmatic children. No significant differences were found among nonatopic children (2-way analysis of variance). Bars indicate (from bottom to top) 10th, 25th, 50th (median), 75th, and 90th percentiles. Values below 10th and above 90th percentiles are plotted as circles. For each subgroup, the number of children is indicated (\#). $* P<.001$.

\section{Statistical Analyses}

Analysis of variance and frequency distribution tables $\left(\chi^{2}\right.$ test) for parametric variables were performed. Because the distribution of eNO values was highly skewed, results were expressed as values after natural log transformation (ln eNO). Correlations among variables were investigated by simple linear regression analysis. To study the independent variables able to influence the risk for elevated eNO levels, eNO was

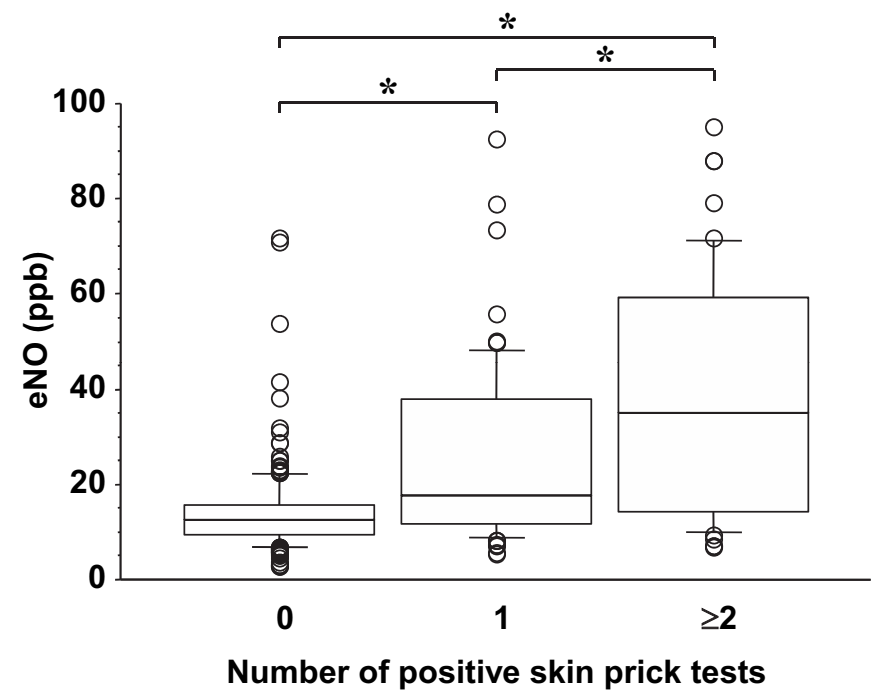

Figure 2. Values of exhaled nitric oxide level (eNO) are shown separately for nonatopic children (0), for children with only 1 positive skin test result (1), and for children with 2 or more positive skin test results $(\geq 2)$. Bars indicate (from bottom to top) 10th, 25th, 50th (median), 75th, and 90th percentiles. Values below 10th and above 90th percentiles are plotted as circles. $* P<.001$ (differences among groups were computed by analysis of variance after natural log transformation). dichotomized at the level of the 75th percentile and the logistic regression model was used to explore the relation between the dependent variable (eNO) and independent variables (atopy, asthma, and sex), adjusting for confounding variables (pulmonary function, lung size, and height). For this purpose, continuous independent variables were dichotomized at the level of the 50th percentile of their distribution. All computations were performed with the use of the StatView statistical software package (SAS Institute Inc, Cary, North Carolina). $P<.05$ was selected as statistically significant.

\section{RESULTS}

Participants $(\mathrm{n}=335)$ in whom eNO measurement was performed were not significantly different compared with the whole sample $(\mathrm{N}=1,050)$ regarding age, sex, atopy, rhinitis

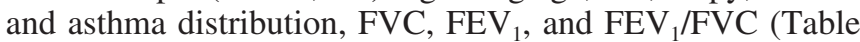
1). In the studied sample, mean $\mathrm{FEV}_{1}$, in percentage of predicted, was $98.7 \%$ (SD, 10.8\%) and $\mathrm{FEV}_{1} / \mathrm{FVC}$ was $90.1 \%$ (SD, 5.34\%). There were 125 atopic children (37.3\%). No significant difference in the prevalence of atopy was found between the sexes (Table 1). Among atopic children, $102(82 \%)$ had a positive skin test result for Dermatophagoides.

As indicated in Table 2, 46 of 335 children (13.7\%) reported asthma with or without rhinitis, 157 (46.9\%) reported rhinitis alone, and the remaining 132 (39.4\%) were asymptomatic. Asthmatic children had a significantly lower $\mathrm{FEV}_{1} /$ FVC (analysis of variance, $P<.002$ ) compared with asymptomatic and rhinitic children. The prevalence of atopy, as defined herein, was $28.8 \%$ in asymptomatic (control) children, $40.1 \%$ in rhinitic children, and $52.2 \%$ in asthmatic children $\left(P=.01, \chi^{2}\right.$ test $)$.

Atopic children, regardless of clinical presentation, had significantly higher eNO than did nonatopic children (Fig 1): median (interquartile range) eNO was $12.6 \mathrm{ppb}(9.3-15.7$ $\mathrm{ppb})$ in nonatopic children and $21.2 \mathrm{ppb}(13.2-44.3 \mathrm{ppb})$ in atopic children $(P<.001$, by Mann-Whitney $U$ test $)$. Among those atopic children, asthmatic children showed the highest ln eNO mean value $(3.69, P<.001$, by analysis of variance) (Fig 1), which was significantly different from rhinitic and control children. Conversely, no significant difference was found between rhinitic and control children. When considering nonatopic children, no significant difference was found for ln eNO among control, rhinitic, or asthmatic children (by analysis of variance) (Fig 1).

As mentioned herein, children were divided into 3 different groups according to skin positivity (nonatopic, 1 positive skin test result, and 2 or more positive skin test results). The level of $\ln$ eNO was significantly increased in children with 1 positive prick test result and even higher in children with multiple positive skin test results compared with nonatopic children. Differences in eNO levels among the 3 skin prick groups are shown in Figure 2. The linear correlation between ln eNO and number of positive skin test results (as continuous variable) was statistically significant $(P<.001)$, both in the 
Table 3. Multiple Logistic Regression Analysis (Association With Increase in Exhaled Nitric Oxide Levels, Cutoff Level at 75th Percentile)

\begin{tabular}{llc}
\hline \multicolumn{1}{c}{ Allergen } & \multicolumn{1}{c}{ OR $(\mathbf{9 5 \%} \mathbf{~ C l )}$} & $\boldsymbol{P}$ value \\
\hline Dermatophagoides & $6.18(3.26-11.7)$ & $<.001$ \\
Cat dander & $8.70(1.93-39.14)$ & $<.005$ \\
Parietaria & $1.30(0.41-4.08)$ & .65 \\
Alternaria & $4.10(0.34-49.09)$ & .26 \\
Grass pollen & $0.74(0.19-2.85)$ & .66 \\
Compositae & $1.16(0.04-30.96)$ & .93 \\
Olea & $0.76(0.18-3.13)$ & .71 \\
Blattella germanica & $1.84(0.15-22.80)$ & .63
\end{tabular}

Abbreviations: $\mathrm{Cl}$, confidence interval; OR, odds ratio.

a Data are expressed as OR adjusted for sex, asthma, and rhinitis.

overall sample and in each subgroup (control children: $r=$ .449; rhinitic children: $r=.381$; and asthmatic children: $r=$ .677).

Using the simple linear regression analyses, we did not find any relation between $\ln$ eNO (as the dependent variable) and height, FVC, $\mathrm{FEV}_{1}$ (percentage of predicted), $\mathrm{FEV}_{1} / \mathrm{FVC}$, and $\mathrm{FEV}_{1} / \mathrm{FVC}$ (percentage of predicted) as independent variables. When eNO was used as the dependent variable in a logistic model, the presence of atopy (odds ratio [OR], 7.63; $95 \%$ confidence interval $[\mathrm{CI}], 4.24-13.74 ; P<.001)$, the presence of asthma (OR, 3.34; 95\% CI, 1.54-7.24; $P<$ $.001)$, and male sex (OR, 2.21; 95\% CI, 1.23-3.97; $P=.001)$ were significant predictors of increased eNO, after adjustment for $\mathrm{FEV}_{1} / \mathrm{FVC}, \mathrm{FVC}$, and height. To evaluate the interaction between presence of atopy and asthma, we introduced into the logistic model a categorical variable in 4 levels $(0$, no atopy, no asthma, $\mathrm{n}=188$ [reference category]; 1, asthma without atopy, $\mathrm{n}=22 ; 2$, atopy without asthma, $\mathrm{n}=101$; and 3 , atopy with asthma, $\mathrm{n}=24)$. The ORs $(95 \% \mathrm{CIs})$ were 0.5 (0.05-3.9) for level 1, 5.1 (2.8-9.5) for level 2, and 64.1 (16.8-244.9) for level 3. Among allergens, Dermatophagoides and cat dander were significant predictors of increased eNO when adjusted for sex and the presence or absence of asthma and rhinitis (Table 3 ).

\section{DISCUSSION}

This cross-sectional study in schoolchildren demonstrates that atopy, sensitization to indoor allergens, asthma, and male sex are significant predictors for increased eNO levels in children from a general population. With regard to internal validity, no significant difference was found among the whole sample and the children in whom eNO measurements were performed regarding age, sex, atopy, rhinitis and asthma distribution, $\mathrm{FVC}, \mathrm{FEV}_{1}$, and $\mathrm{FEV}_{1} / \mathrm{FVC}$.

Levels of eNO are higher in atopic than in nonatopic children. Furthermore, a significant relation exists between eNO levels and number of positive skin test results. In addition, only indoor perennial allergens (ie, Dermatophagoides and cat dander) are associated with significantly increased eNO levels. Furthermore, the highest eNO levels are ob- served in atopic children with physician-diagnosed asthma. In particular, even in the subgroup of asymptomatic individuals, atopic individuals have significantly higher eNO levels (the median eNO was 33\% higher in asymptomatic atopic children than in nonatopic children). This finding suggests that atopy per se is able to significantly influence eNO levels. Similar results were previously reported in both adults ${ }^{13,14}$ and children. ${ }^{2-4}$ However, other studies did not find a relation between atopy and eNO levels in children.1,5,15 In particular, Latzin et $\mathrm{al}^{15}$ failed to demonstrate a relation between atopy and eNO levels in 4- to 18-year-old healthy children. A possible explanation for these conflicting results might be found in the dimension of the studied sample, ${ }^{5}$ the different prevalence of atopic children in the study samples, and the different age distributions. ${ }^{15}$ In fact, in our study, the prevalence of atopy was $29 \%$ among asymptomatic children, and the age range was 10 to 16 years: The corresponding figures in the study by Latzin et al were $46 \%$ and 4 to 18 years, respectively.

We found that boys have significantly higher eNO levels than do girls. This result is in agreement with the works of Barreto et $\mathrm{al}^{4}$ and Wong et al, ${ }^{16}$ who recently demonstrated a sex difference in eNO levels in schoolchildren. Similarly, Nordvall et al, ${ }^{17}$ in a large population sample, found a significantly higher eNO in boys than in girls. The authors attributed this finding to a possible role of larger lung volumes in boys. However, after correcting also for FVC, as an index of lung volume, in our logistic model, we found that male sex maintains a significant effect in increasing eNO values. Nevertheless, controversial results exist on the relation between sex and eNO levels; in fact, in some studies no association was found between sex and eNO. ${ }^{18,19}$ In the study by Malmberg et al, ${ }^{18}$ the authors demonstrated that height was a strong predictor of increased eNO in healthy children. The latter association was not found in our study. The difference may be due to the wider age range (7-16 years) in the study by Malmberg et al, producing a wider height range. Similarly, Buchvald et $\mathrm{al}^{20}$ found a significant correlation between eNO levels and age. We did not find such correlation. Once more, this difference may be explained by the wider age range (4-17 years) in the study by Buchvald et al.

Our results show that children with rhinitis alone do not have eNO values significantly different from control children, both in atopic and nonatopic subgroups (Fig 1). Conversely, Jouaville et $\mathrm{al}^{1}$ demonstrated that atopic children with rhinitis have higher eNO levels than do atopic control children. This difference may be explained by the methodologic differences in eNO measurement and by the smaller sample size in the study by Jouaville et al. Buchvald et al, ${ }^{20}$ in a sample of 405 children ages 4 to 17 years, showed a significant difference between rhinitic and control children. In the latter study, however, the presence of atopy was evaluated on the basis of self-reported symptoms.

It is noteworthy that asthmatic, nonatopic children show eNO levels close to those of nonatopic rhinitic and asymptomatic children. This finding is in agreement with the study 
by Ludviksdottir et al, ${ }^{21}$ who did not observe any significant difference in eNO between nonasthmatic control patients and nonatopic adult asthmatic patients. Furthermore, when rhinitis and especially asthma were associated with atopy, we found much greater eNO levels; in fact, median eNO in atopic, asthmatic patients was approximately 4-fold higher than the level of nonatopic, asthmatic patients (Table 2). Thus, the association of asthma and atopy appears to be the most consistent predictor of increased eNO level. A similar result was obtained by Frank et al, ${ }^{5}$ who found that the eNO geometric mean was significantly higher in children with atopic asthma than in nonatopic asthmatic children. These findings further support the hypothesis that in children atopy is a major determinant of increased eNO levels, mainly when associated with clinical manifestation of asthma. In other words, atopy and asthma appear as cofactors in determining elevated eNO levels.

In the present study, we also found that eNO level increased with the number of positive skin prick test results regardless of clinical status; in fact, when the number of individual positive skin prick test results was used as the continuous independent variable, the linear regression with eNO (as the dependent one) was significant both in the overall sample and in each subgroup (ie, allergic, rhinitic, and control children). This result is consistent with previous studies demonstrating the effect of the number of positive skin test results on the level of eNO. ${ }^{1,2,4,7,22}$ In particular, Franklin et $\mathrm{al}^{2}$ found that in healthy children eNO levels were higher in those with a positive skin prick test result and even higher in children with more than 1 positive skin test result, suggesting that allergen sensitization may play a significant role in elevating eNO production in the respiratory tract.

The logistic analysis model also showed that after adjusting for confounding variables, only sensitization to Dermatophagoides and cat dander influence eNO levels. Similarly, Leuppi et $\mathrm{al}^{23}$ showed that in atopic children, an increased eNO level is associated with sensitization to perennial allergens but not with seasonal allergens. In addition, Barreto et al ${ }^{19}$ reported no difference in eNO levels between nonatopic and atopic children sensitized to grass pollen. Thus, sensitization to indoor perennial allergens appears to affect eNO production in the respiratory tract, possibly through longlasting inflammatory stimuli, regardless of clinical respiratory manifestations. This finding is in agreement with the study by Gratziou et al, ${ }^{6}$ who suggested that eNO levels mainly reflect the allergic origin of inflammation in the airways.

In conclusion, atopic status is strongly associated with high eNO levels, even in asymptomatic individuals. The relation between atopy and eNO levels indicates that eNO measurements may help to clarify the relevant role of sensitization in the complex interplay of multiple factors determining the translation into clinical allergy. Furthermore, this finding also helps to address the problem of asymptomatic allergen sensitization vs clinical allergy, also envisaging the possible role of eNO measurement as a noninvasive screening test for early detection of individuals prone to have clinical allergy. In particular, the sensitization to indoor perennial allergens appears to be one of the main determinants of high eNO levels. Furthermore, the eNO levels were positively correlated with the number of positive skin prick test results. Consequently, we recommend performing eNO measurements in epidemiologic studies on respiratory diseases in children, taking into account the individual's atopic status. The development of new portable instruments for eNO monitoring ${ }^{24}$ opens new perspectives to widespread use of such measurements in epidemiology.

\section{ACKNOWLEDGMENTS}

We thank Dr Marzia Simoni for kind support in statistical analysis and Mr Roberto Perissin and Dr Gabriele Nicolini for technical support. The allergens for skin prick tests were kindly provided by Dr Franco Frati (Stallergènes Italia S.r.l., Milan, Italy). We also express our gratitude to Dr Anna Lucania and Dr Girolamo Panascì for excellent medical assistance.

\section{REFERENCES}

1. Jouaville LF, Annesi-Maesano I, Nguyen LT, et al. Interrelationships among asthma, atopy, rhinitis and exhaled nitric oxide in a populationbased sample of children. Clin Exp Allergy. 2003;33:1506-1511.

2. Franklin PJ, Taplin R, Stick SM. A community study of exhaled nitric oxide in healthy children. Am J Respir Crit Care Med. 1999;159:69-73.

3. Prasad A, Langford B, Stradling JR, Ho LP. Exhaled nitric oxide as a screening tool for asthma in school children. Respir Med. 2006;100: $167-173$

4. Barreto M, Villa MP, Monti F, et al. Additive effect of eosinophilia and atopy on exhaled nitric oxide levels in children with or without a history of respiratory symptoms. Pediatr Allergy Immunol. 2005;16:52-58.

5. Frank TL, Adisesh A, Pickering AC, et al. Relationship between exhaled nitric oxide and childhood asthma. Am J Respir Crit Care Med. 1998; 158:1032-1036.

6. Gratziou C, Lignos M, Dassiou M, Roussos C. Influence of atopy on exhaled nitric oxide in patients with stable asthma and rhinitis. Eur Respir J. 1999;14:897-901.

7. Janson C, Kalm-Stephens P, Foucard T, et al. Exhaled nitric oxide levels in school children in relation to $\mathrm{IgE}$ sensitisation and window pane condensation. Respir Med. 2005;99:1015-1021.

8. Lanz MJ, Leung DY, McCormick DR, et al. Comparison of exhaled nitric oxide, serum eosinophilic cationic protein, and soluble interleukin-2 receptor in exacerbations of pediatric asthma. Pediatr Pulmonol. 1997;24:305-311.

9. Ferris BG. Epidemiology Standardization Project: recommended respiratory disease questionnaires for use with adults and children in epidemiological research. Am Rev Respir Dis. 1978;118:7-53.

10. Position paper: Allergen standardization and skin tests. The European Academy of Allergology and Clinical Immunology. Allergy. 1993;48: 48-82.

11. American Thoracic Society. Standardization of spirometry: 1994 Update. Am J Respir Crit Care Med. 1995;152:1107-1136.

12. Baraldi E, de Jongste JC. Measurement of exhaled nitric oxide in children, 2001: ERS/ATS Statement. Eur Respir J. 2002;20:223-237.

13. Horvath I, Barnes PJ. Exhaled monoxides in asymptomatic atopic subjects. Clin Exp Allergy. 1999;29:1276-1280.

14. Salome CM, Roberts AM, Brown NJ, Dermand J, Marks GB, Woolcock AJ. Exhaled nitric oxide measurements in a population sample of young adults. Am J Respir Crit Care Med. 1999;159:911-916.

15. Latzin P, Beck J, Griese M. Exhaled nitric oxide in healthy children variability and a lack of correlation with atopy. Pediatr Allergy Immu- 
nol. 2002;13:37-46.

16. Wong GW, Liu EK, Leung TF, et al. High levels and gender difference of exhaled nitric oxide in Chinese schoolchildren. Clin Exp Allergy. 2005;35:889-893.

17. Nordvall SL, Janson C, Kalm-Stephens P, et al. Exhaled nitric oxide in a population-based study of asthma and allergy in schoolchildren. $\mathrm{Al}$ lergy. 2005;60:469-475.

18. Malmberg LP, Petays T, Haahtela T, et al. Exhaled nitric oxide in healthy nonatopic school-age children: determinants and height-adjusted reference values. Pediatr Pulmonol. 2006;41:635-642.

19. Barreto M, Villa MP, Martella S, et al. Exhaled nitric oxide in asthmatic and non-asthmatic children: influence of type of allergen sensitization and exposure to tobacco smoke. Pediatr Allergy Immunol. 2001;12: 247-256.

20. Buchvald F, Baraldi E, Carraro S, et al. Measurements of exhaled nitric oxide in healthy subjects age 4 to 17 years. J Allergy Clin Immunol. 2005;115:1130-1136.

21. Ludviksdottir D, Janson C, Hogman M, et al. Exhaled nitric oxide and its relationship to airway responsiveness and atopy in asthma. Respir Med. 1999;93:552-556.
22. van Amsterdam JG, Janssen NA, de Meer G, et al. The relationship between exhaled nitric oxide and allergic sensitization in a random sample of school children. Clin Exp Allergy. 2003;33:187-191.

23. Leuppi JD, Downs SH, Downie SR, Marks GB, Salome CM. Exhaled nitric oxide levels in atopic children: relation to specific allergic sensitisation, AHR, and respiratory symptoms. Thorax. 2002;57:518-523.

24. Khalili B, Boggs PB, Bahma SL. Reliability of a new hand-held device for the measurement of exhaled nitric oxide. Allergy. 2007;62: $1171-1174$.

Requests for reprints should be addressed to:

Fabio Cibella, MD

Istituto di Biomedicina e Immunologia Molecolare "Alberto Monroy" del C.N.R

via Ugo La Malfa, 153

90146 Palermo, Italy

E-mail: cibella@ibim.cnr.it 